https://www.journal-imab-bg.org

Original article

OPEN ACCESS

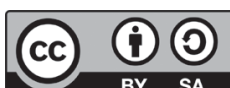

\title{
COMPARISON BETWEEN WEB-BASED AND PAPER QUESTIONNAIRES FOR THE ASSESSMENT OF BURNOUT SYNDROME USING BOYKO'S METHODOLOGY
}

\author{
Rumyana Stoyanova ${ }^{1}$, Stanislava Harizanova ${ }^{2}$ \\ 1) Department of Health Management and Health Economics, Faculty of Public \\ Health, Medical University of Plovdiv, Bulgaria \\ 2) Department of Hygiene and Ecomedicine, Faculty of Public Health, Medical \\ University of Plovdiv, Bulgaria.
}

\begin{abstract}
Introduction: Questionnaires are often used to quantify the subjective aspects of burnout syndrome. Data collection using webbased questionnaires generally improves data quality, because data are entered electronically and may automatically be transformed into an analyzable format, and errors in the process of data entry and coding are avoided as well.

Purpose: The aim of the study is to compare the completeness of data and consuming time of web-based and paper questionnaires for burnout syndrome based on Boyko's inventory

Material and methods: In study took part 30 patients from one ambulatory practice, who completed the two versions of the questionnaire and their physician. Data completeness was assessed by comparing the number of missing values between the two methods. Consuming time was assessed by comparing the duration of completing and analyzed the data from the web-based and paper questionnaires.

Results: Paper questionnaires generally had more missing values $(\mathrm{P}<.05)$. Web-based questionnaires were completely filled out due to pop-up notifications that appeared directly onto questions with missing values. Duration of completing and processing a returned paper questionnaire was 3.5 times that of a returned web-based questionnaire.

Conclusion: The web-based system can be less time-consuming and a source of fewer errors than paper questionnaires and permits review of the data and compliance during the study.
\end{abstract}

Keywords: burnout, Boyko's inventory, web-based questionnaire, eHealth,

\section{INTRODUCTION:}

Burnout is a phenomenon that seems to be studied globally in relation to all types of populations - managers, employees, and workers in a variety of industries and sectors. Studies on occupational burnout among Bulgarian employees are rather scarce, except for those related to health professionals, teachers and correctional officers [14]. Professionals increasingly used the term burnout to describe the feelings that resulted in from growing demands in the workplace.Affected people usually suffer from workrelated stress, fatigue, and exhaustion, the most prominent signs of which are often referred to as burnout syndrome [5-7].

Often used tools to quantify the subjective aspects of burnout syndrome are the questionnaires.

The most of the methods available at present only register the irreversible changes that have already set in the functioning of the individuals, but the global aim of this study was to create an information system using the method which allows better assessment and management of burnout.

Therefore, the existing methods of Burnout Syndrome assessment, as well as their advantages and disadvantages were analyzed. A targeted search for the used methods for prevention and diagnosis of Burnout was made. The results of the analysis showed that the most commonly used methodologies for diagnosing the syndrome are presenting in the table 1 .

Table 1. Comparison among the existing methods of Burnout Syndrome assessment.

\begin{tabular}{|c|c|c|c|c|c|c|}
\hline Tools & $\begin{array}{l}\text { Number of } \\
\text { questions }\end{array}$ & $\begin{array}{c}\text { Number of } \\
\text { scales }\end{array}$ & $\begin{array}{l}\text { Universally } \\
\text { applicable }\end{array}$ & $\begin{array}{l}\text { Validity, } \\
\text { reliability }\end{array}$ & $\begin{array}{c}\text { Easy } \\
\text { to apply }\end{array}$ & $\begin{array}{c}\text { Psycho } \\
\text { prophylaxis }\end{array}$ \\
\hline MBI & 22 & 3 & Yes & Good & Yes & No \\
\hline BM & 22 & 1 & Yes & Good & Yes & No \\
\hline MBI-Human Services Survey & 22 & 3 & No & Unsatisfactory & Yes & No \\
\hline Oldenburg Burnout Inventory & 16 & 2 & Yes & Good & Yes & No \\
\hline Copenhagen Burnout Inventory & 19 & 3 & Yes & Good & Yes & No \\
\hline Boyko's Inventory & 84 & 3 & Yes & Good & Yes & Yes \\
\hline
\end{tabular}


Analyzing their strengths and weaknesses was found that a common disadvantage of the methodologies was that they find out the irreversible changes in the functioning of the individual. The only method that can be used for psychoprophylaxis and psycho-correction of Burnout syndrome is that of the Russian scientist Boyko. On the other hand, the clarity and uniformity of interpretation of the scales make this inventory easier for clinicians to compare the obtained results with other psychodiagnostic techniques.
In the meantime, in the era of eHealth practices, some researchers proved that a web-based application could be an attractive form for identified of individuals at risk for burnout. They reckon that these applications can play an important role for those who need and can initiate internet-guided interventions as preventive steps [8].

Referring to this statement and the results obtained above,the Boyko's methodology was used for, creating of a web-based information system for registration, analysis and diagnosis of Burnout in Bulgaria (see figure 1).

Fig. 1. The screenshot of the main page.

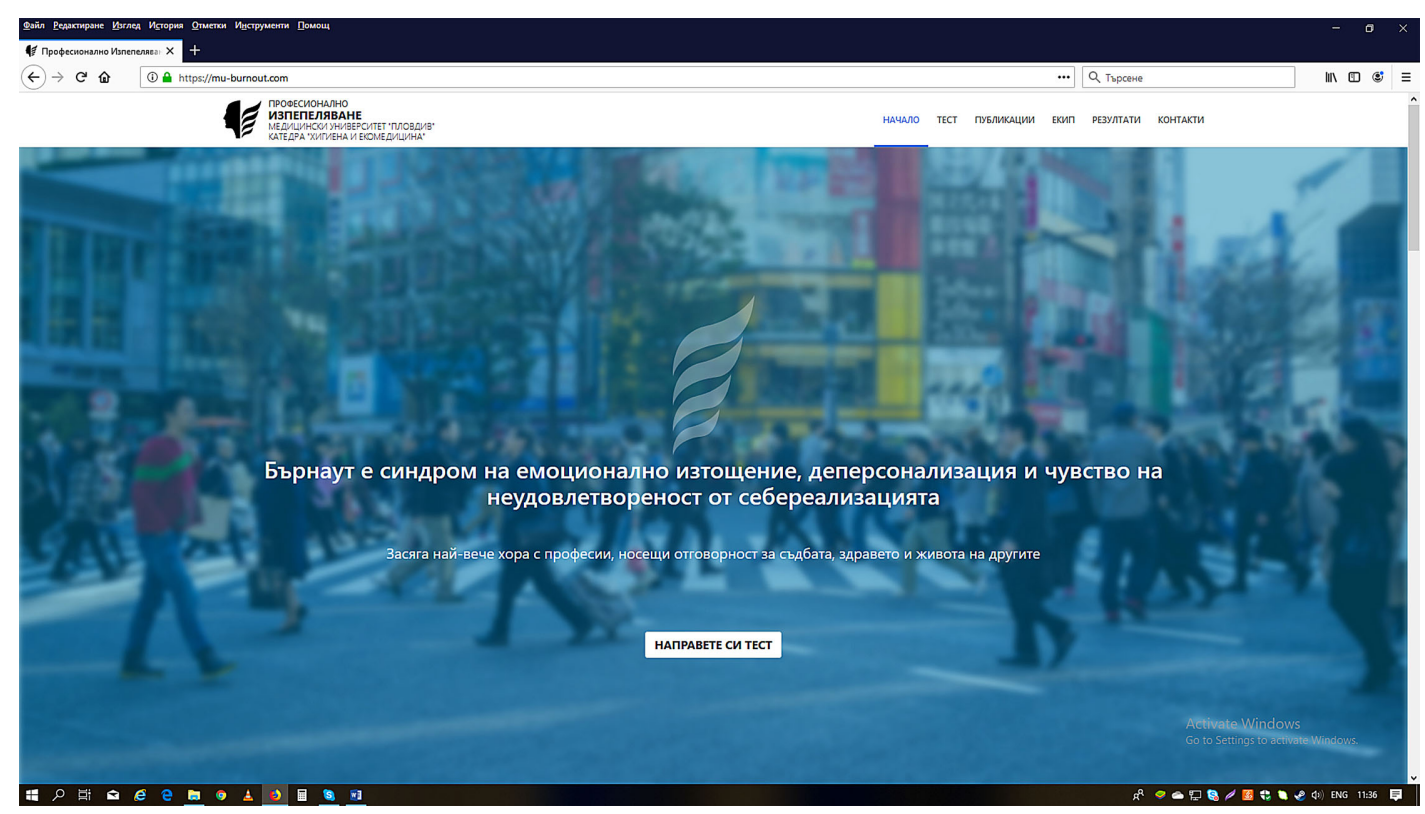

The aim of this study is to compare the completeness of data and consuming time of web-based and paper questionnaires for burnout syndrome based on Boyko's inventory.

Data completeness is assessed by comparing the number of missing values between the two methods.

Consuming time is assessed by comparing the duration of completing and analyzed the data from the webbased and paper questionnaires.

\section{MATERIAL AND METHODS:}

For the present test study, two versions of Boyko's inventory were used: a paper version and a web-based version. For this purpose, a special web-based platform for assessment of burnout was developed. It is free-to-access and available on website: https://mu-burnout.com/

The Boyko's inventory included 84 items to evaluate the phases and assess the degree of severity of the symptoms of burnout. Each item in its positive or negative aspect carries a different, number of points $(1,2,3,5$ or 10 points), which allows the formation of a total score (range 0 to 30 points) for each of the symptoms. The higher the total score, the more pronounced, is the symptom. After the total score by symptoms is obtained, the questionnaire starts forming a total score by phases. The rating by phases can be from 0 to 120 points. The quantitative indicators can indicate how complete a phase is, that is, what the level of development of the phase is.

In the study took part 30 patients from one ambulatory practice and their physician. The patients were asked to fill in both versions of the questionnaire. The paper version was given to them first and immediately after that the web-based.

The web-based version does not allow incomplete answers from all items of the questionnaire. In this way, if this condition could not meet, the respondent has been alerted by an alarm message indicating the nature of the problem and the necessity to correct before submitting the questionnaire (see figure 2). 
Fig. 2. The screenshot of the alarm message.

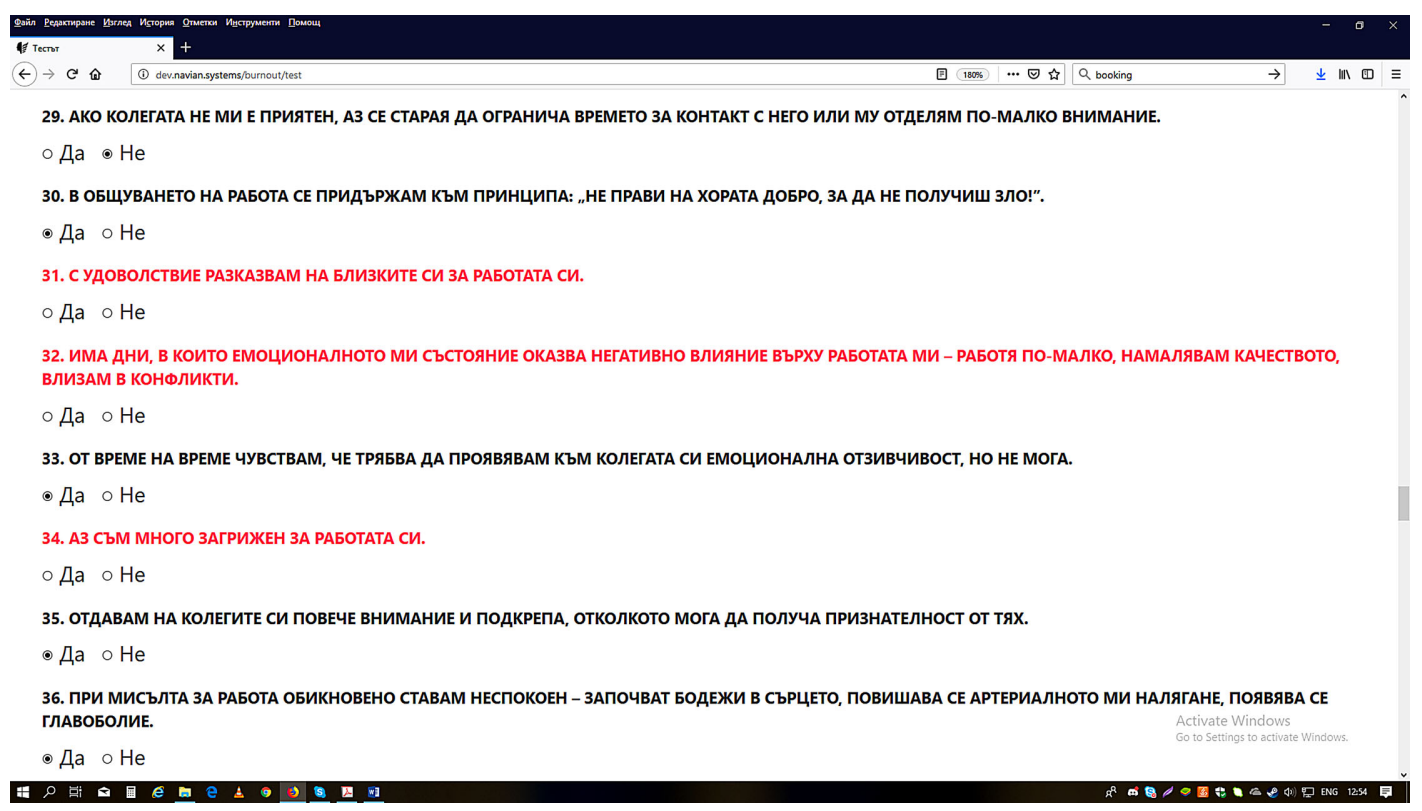

Data collection comprised recording participants' information simultaneously on paper and electronic forms. Data from the web-based platform were directly imported in SPSS v.17.0 database. The answers to the paper version were analyzed by their physician, who had to check the completeness of the paper questionnaire, estimated the Burnout results and total time for analyzing the questionnaires.

\section{RESULTS:}

The results showed that there are significant differ- ences between two the methods - web-based and paperbased version. Significant part of paper questionnaires has missing values $-23.34 \%(n=7)$ compared to web-based version - $0 \%(n=0)$. The reason is that the web-based version does not allow incomplete answers. The difference between the invalid paper questionnaires and web-based version is significant $(\mathrm{P}<.05)$.

Duration of completing and obtained the results of the web-based questionnaire is approximately $12 \pm 0.467$ min because the result time is instant (see figure 3 ).

Fig. 3. The screenshot of the results page.

РЕЗУЛТАТЫТ

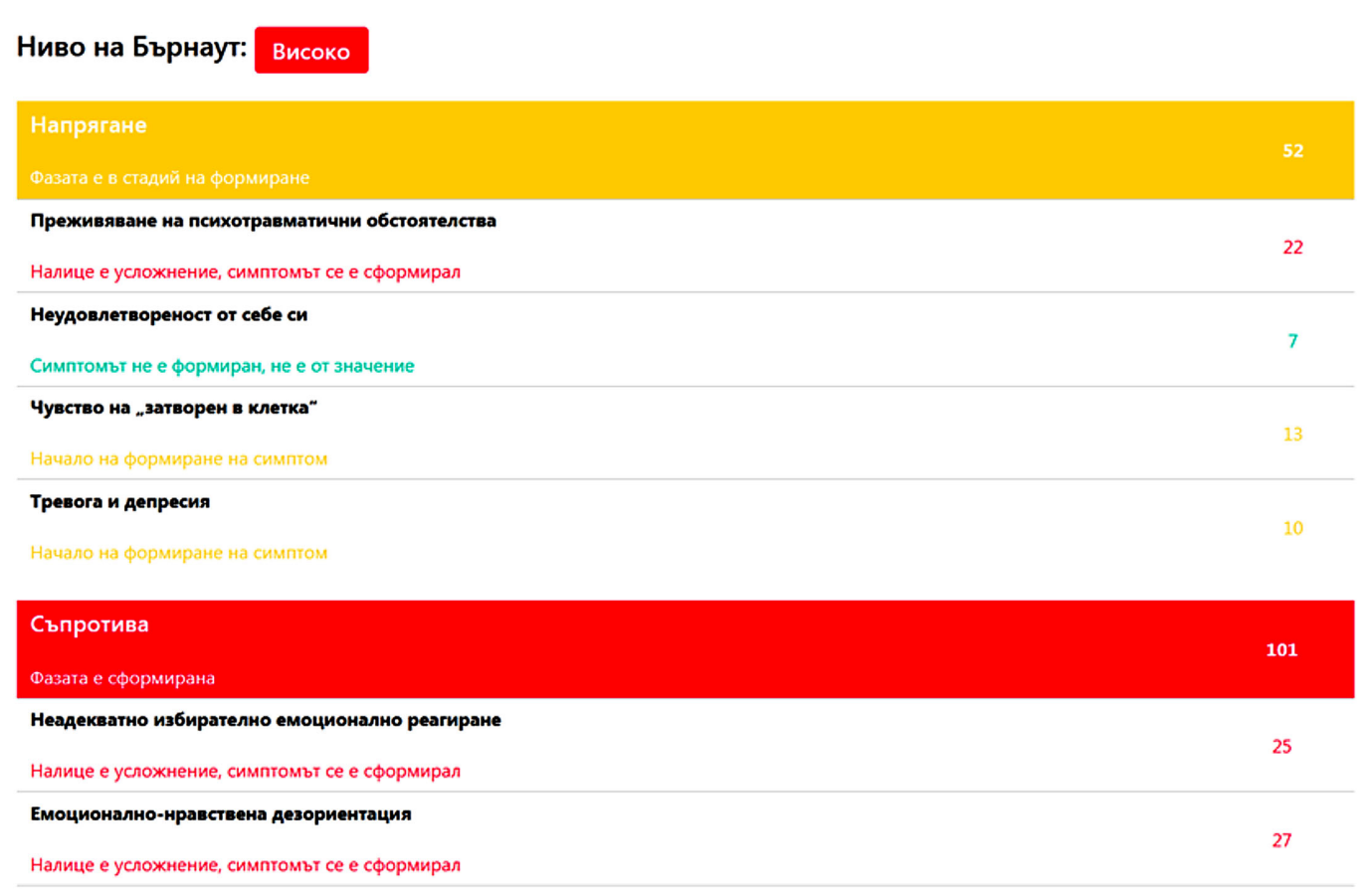


Duration of completing of the paper questionnaire is average $15 \pm 1.236 \mathrm{~min}$. After that, the physician needed $25 \pm 1.437$ min per questionnaire to check it and estimate the results.

Duration of completing and processing of the paper questionnaire is almost 3.5 times than of the web-based questionnaire.

\section{DISCUSSION:}

Similar to studies from other countries, our results found, that using paper-based questionnaires lead to a higher frequency of incomplete records, greater human errors potential, and more time to organize the data $[9,10]$. In the meantime, the web-based questionnaires are evidently economic and environmentally friendly and can provide faster reporting with more accuracy. Visual and audio applications and pop-up windows providing important information may be added to improve responding, which is impossible in paper-and-pencil questionnaires [11].

The study found that the use of a web-based data collection method is feasible and provides timely and quality data without errors and inconsistencies. On the other hand, web-based data collection provided more timely data for analysis in comparison to the paper-based forms.

The potential of such web applications to maintain or improve health, and change health behaviours of users is big and start to change the way healthcare is delivered [12]. The possibility of an anonymous burnout assessment is attractive if, for instance, users must fear disadvantages when communicating health problems to company medical officers.

On the other hand, where geographical boundaries exist, the web application could also be used for early iden- tification of a burnout risk state and initiation of appropriate measures, which mean to seek timely help from a doctor or mental health specialist who could provide the instructions over the internet.

In the realm of electronic healthcare practices supported through the internet, uncomplicated access to a webbased guided self-help intervention to alleviate burnout symptoms is a timely means to potentially improve employee health, prevent sick leave, and lower health expenditures for companies and society $[8,13]$.

\section{CONCLUSIONS:}

The web-based application is useful to assess the risk of job burnout. While the traditional way to collect data is a paper-based questionnaire, it is not suitable for psychological tests, because:

- It may contain a higher frequency of incomplete answers that make it invalid;

- There is a greater potential for human errors when entering, computing, and analyzing data;

- More time is needed to obtain the results.

The benefits of web-based questionnaires compared to paper surveys include saving time (faster) - the response time is almost instant; quick to analyze; more accurate eliminate the possibility of human error; cheaper - a costeffective way to collect data; easy to use for respondents and easy to use for researchers.

\section{FUNDING SOURCE:}

This study has been conducted with the financial support of the Scientific Research Fund of the Plovdiv Medical University under research project NO-13/2018.

\section{REFERENCES:}

1. Dimova R, Mateva N, Bakova D, Tilov B. Burnout in Healthcare Employees Working in Surgical Departments, Anesthesiology and Intensive Care. In: New Model of Burn Out Syndrome: Towards early diagnosis and prevention. Stoyanov D, ed. River Publishers. January 2014. Chapter 5. p.59-70.

2. Harizanova S, Stoyanova R. Burnout among nurses and correctional officers. Work. 2020; 65(1):7177. [PubMed] [Crossref]

3. Stoyanova R. Relationship Between Working Environment Factors, Burnout Syndrome and Turnover Intentions Among Nurses - A Cross-Sectional Study in Bulgaria. In: Bagnara S, Tartaglia R, Albolino S, Alexander T, Fujita Y. (eds). Proceedings of the 20th Congress of the International Er- gonomics Association (IEA 2018). IEA 2018. Advances in Intelligent Systems and Computing, vol 818. Springer, Cham. 2019. pp.35-43. [Crossref]

4. Tsenova, B. Personality correlates of burnout syndrome. In: Dimitrov et al. Eds. Publishing House: Sofia-R. 2005;360-367. [in Bulgarian]

5. Ahola K, Väänänen A, Koskinen A, Kouvonen A, Shirom A. Burnout as a predictor of all-cause mortality among industrial employees: A 10year prospective register-linkage study. J Psychosom Res.2010 July; 69(1):51-57. [PubMed] [Crossref]

6. Kant IJ, Bültmann U, Schröer K, Beurskens A, Van Amelsvoort L, Swaen G. An epidemiological approach to study fatigue in the working population: The Maastricht Cohort Study. Occup Environ Med. 2003 June;
60(Suppl. 1):i32-i39. [PubMed] [Crossref]

7. Langelaan S, Bakker AB, Schaufeli WB, van Rhenen W, van Doornen L. Do burned-out and workengaged employees differ in the functioning of the hypothalamic-pituitaryadrenal axis? Scand J Work Environ Health. 2006 Oct;32(5):339-348. [PubMed] [Crossref]

8. von Känel R, van Nuffel M, Fuchs WJ. Risk assessment for job burnout with a mobile health web application using questionnaire data: a proof of concept study. Biopsychosoc Med. 2016 Nov 2;10(1):31. [PubMed] [Crossref]

9. King JD, Buolamwini J, Cromwell EA, Panfel A, Teferi T, Zerihun M, at al. A novel electronic data collection system for large-scale 
surveys of neglected tropical diseases. PLoS One. 2013 Sep 16;8(9):e74570. [PubMed] [Crossref]

10. Weber BA, Yarandi H, Rowe MA, Weber JP. A comparison study: paper-based versus web-based data collection and management. Appl Nurs Res. 2005 Aug;18(3):182-185. [PubMed] [Crossref]

11. Van Gelder MM, Bretveld RW,
Roeleveld N. Web-based questionnaires: the future in epidemiology? Am J Epidemiol. 2010Sep;172(11):12921298. [PubMed] [Crossref]

12. mHealth App Developper Economics 2015. The current status and trends ofthe mHealth app market. 5th annual study on mHealth app publishing based on 5000 plus respondents. research2guidance. November 2015. [Internet]

13. Martínez-Pérez B, de la TorreDíez I, López-Coronado M. Mobile health applications for the most prevalent conditions by the World Health Organization: review and analysis. $J$ Med Internet Res. 2013 Jun 14;15(6): e120. [PubMed] [Crossref]

Please cite this article as: Stoyanova R, Harizanova S. Comparison between web-based and paper questionnaires for the assessment of burnout syndrome using Boyko's methodology. J of IMAB. 2020 Jan-Mar;26(1):2970-2974.

DOI: https://doi.org/10.5272/jimab.2020261.2970

Received: 05/09/2019; Published online: 13/03/2020

\section{Address for correspondence:}

Rumyana Stoyanova

Department of Health Management and Health Economics, Faculty of Public Health, Medical University of Plovdiv,

15A, Vasil Aprilov blvd., Plovdiv 4002, Bulgaria

E-mail: rumi_stoqnova@abv.bg 